\title{
Risk Sharing Method of PPP Model for Rural Sewage Treatment - Based on Interval Fuzzy Shapley Value
}

\author{
Xiaolin Chu* \\ Beijing Wuzi University, Beijing 101149, China \\ *Corresponding author: Xiaolin Chu, chuxllinda@aliyun.com
}

\begin{abstract}
Rural sewage treatment is in need of more capital investment, in which the financing model of PPP (public-private partnership) is able to encourage the investment of social capital in this sector. Risk sharing is one of the core features in the PPP model. In view that the risk loss of projects cannot be accurately estimated, this article describes the uncertainty of risk loss with fuzzy numbers and allocates the distribution of risk loss among the participants of rural sewage treatment PPP projects with interval fuzzy Shapley value to ensure a more reasonable and effective risk distribution.
\end{abstract}

Keywords: Rural sewage treatment; PPP; Risk sharing; Interval fuzzy Shapley value

Publication date: October 2021; Online publication: October 29, 2021

\section{Introduction}

If rural domestic sewage is not treated in time, pollutants in sewage discharge, chemical fertilizers, and pesticides would affect the quality of surface water as well as groundwater, threatening the health of farmers and the safety of their crops. Rural sewage treatment is in need of more capital investment. In addition to financial funds, more social capital needs to be invested in this industrial sector. The PPP model, which involves the mutual cooperation between public and private sectors, refers to the establishment of a partnership between the government and social capital for public infrastructure projects to achieve mutual benefits and win-win results through franchise agreements. This model can effectively increase and optimize the supply of public goods and services with social capital. Therefore, the adoption of PPP financing model in the rural sewage treatment sector can encourage more social capital to be invested. Due to large investments as well as long periods of construction and operation, PPP projects have complex and a large number of risk factors. In order to better control the risk, it is necessary to create a fair and reasonable risk sharing scheme for the government and social departments. A reasonable risk sharing scheme is the key to ensure the successful implementation of PPP projects. In researching about risk sharing methods, local and foreign scholars have mainly used quantitative research methods of statistics as well as the game theory. Jin analyzed the proportion of risk sharing in PPP projects with TCE (transaction cost economics) and RBV (resource-based view) models ${ }^{[1]}$. He Tao and another researcher studied the risk sharing scheme of public and private parties in PPP projects based on the cooperative game theory; they believe that this scheme helps in reducing the total risk of projects ${ }^{[2]}$. Wang Lei and other researchers analyzed the risk sharing scheme of public and private parties by using the cooperative game theory and analytic network process (ANP). In that article, the influencing factors of risk sharing were divided into five types: cooperation mechanism and so on ${ }^{[3]}$. Liu Chuang and other researchers studied the risk allocation of water diversion PPP projects by using the combination of analytic hierarchy process-group eigenvalue method 
(AHP-GEM) and interval fuzzy Shapley value ${ }^{[4]}$.

In PPP projects, it is often not possible for each participant to accurately estimate the actual value of risk loss. In view of this characteristic where the project risk loss cannot be accurately estimated, this article describes the uncertainty of risk loss with fuzzy numbers and allocates the distribution of risk loss to each participant in rural sewage treatment PPP projects with interval fuzzy Shapley value. It is hoped that the method proposed in this article would be able to ensure a more objective and fair risk distribution, enhance the participants' enthusiasm to participate in these projects, and avoid project failures caused by unfair risk loss sharing.

\section{Construction of risk sharing method}

\subsection{Constructing risk loss fuzzy numbers}

Let the n-person cooperative game to be represented by two tuples $(N, v(S)), N=\{1,2, \ldots n\}$ is the set of participants, $n=|N|$ as the number of participants, alliance $S$ is any subset of $\mathrm{N}, v(S)$ is the payment function, $v(S): P(N) \rightarrow R, \mathrm{v}(\phi)=0$, and $P(N)$ is the set comprising of all subsets of $\mathrm{n} . v(S)$ can be used as the risk loss value of each partner in the project with different alliances. Before risk occurs, the risk loss value of alliance $\mathrm{S}$ often cannot be accurately estimated and there is uncertainty. This uncertainty can be expressed by fuzzy numbers; thus, the cooperative game can be extended to fuzzy payment cooperative game. Let the fuzzy payment cooperative game to be represented by two tuples $(N, \widetilde{v}(S)), \widetilde{v}(S): P(N) \rightarrow F R, \widetilde{v}(\phi)=0$, $F R_{+}$is a set of non-negative fuzzy numbers, $\widetilde{v}(S)$ can be used as the uncertain risk loss value of alliance $\mathrm{S}$. As triangular fuzzy numbers have the advantages of easy representation and processing of fuzzy information, triangular fuzzy numbers can be used to construct the fuzzy numbers $\widetilde{v}(S)$. In order to facilitate calculation, symmetrical triangular fuzzy numbers are further used to construct the fuzzy numbers. Note that the membership function of symmetrical triangular fuzzy numbers $\widetilde{v}(S)$ is $f(x) ; f(x): X \rightarrow[0,1]$, where $x \in X$ and $X$ is the universe. The expression is as follows:

$$
f(x)=\left\{\begin{array}{cl}
\frac{x-a}{\frac{a+b}{2}-a}, & x \in\left(a, \frac{a+b}{2}\right) \\
\frac{b-x}{b-\frac{a+b}{2},} & x \in\left(\frac{a+b}{2}, b\right) \\
0, & \text { others }
\end{array}\right.
$$

Where $\alpha$ is the lower limit of triangular fuzzy numbers, $b$ is the upper limit of triangular fuzzy numbers, and $\frac{a+b}{2}$ is the peak of membership function. The lower limit of triangular fuzzy numbers $\widetilde{v}(S)$ can be replaced by the lower limit of $v(S)$. If $S=\bigcup_{i=1}^{m} S_{i}, S_{i} \cap S_{j}=\phi$, and $\max \sum_{i} v\left(S_{i}\right) \leq v(S), \max \sum_{i} v\left(S_{i}\right)$ can be used as the lower bound of $v(S)$, where $m$ is the number of all possible alliances, $m=2^{|N|}$. The upper limit of triangular fuzzy numbers $\widetilde{v}(S)$ can be replaced by the upper limit of $v(S)$. If $S \subset S_{i}$ so $v(S) \leq \min \left\{v\left(S_{i}\right)-\right.$ $\left.v\left(S_{i} \backslash S\right)\right\}$; it can be used as the upper limit of $v(S)$. 


\subsection{Calculating risk sharing}

The interval fuzzy Shapley value can be used to solve the fuzzy cooperative game. As both interval fuzzy Shapley value and classical Shapley value distribute risk according to the contribution of the partners to risk loss reduction, in actual calculation, the meaning of interval fuzzy $\widetilde{v}(S)$ should be the fuzzy numbers of risk loss reduction value. The above construction of risk loss fuzzy numbers can be referred to for the construction of fuzzy numbers of risk loss reduction value. For $\alpha \in[0,1]$, the $\alpha$ cut set of fuzzy numbers $\widetilde{v}(S)$ is $\widetilde{v}_{\alpha}(S)=\{x \in X \mid f(x) \geq \alpha\}$. It can also be expressed as $\left[\widetilde{v}_{\alpha}^{-}(S), \widetilde{v}_{\alpha^{+}}(S)\right] ;\left[\widetilde{v}_{\alpha}-(S), \widetilde{v}_{\alpha^{+}}(S)\right]$ is the left and right endpoints of the $\alpha$ cut set, respectively. According to the concept of interval fuzzy Shapley value, for $\alpha \in[0,1]$, the interval fuzzy Shapley value can be expressed as $\left[\psi_{i}\left(\widetilde{v}_{\alpha^{-}}\right), \psi_{i}\left(\widetilde{v}_{\alpha} \alpha^{+}\right)\right]$:

$$
\begin{aligned}
& \psi_{i}\left(\tilde{v}_{a}^{-}\right)=\sum_{|S|=\mid i \in S \in N}^{n} \frac{(n-|S|) !(|S|-1) !}{n !}\left[\tilde{v}_{a}^{-}(S)-\tilde{v}_{a}^{-}(S \backslash\{i\})\right] \quad i=1,2, \cdots n \\
& \psi_{i}\left(\tilde{v}_{a}^{+}\right)=\sum_{|S| l \mid i \in S \in N}^{n} \frac{(n-|S|) !(|S|-1) !}{n !}\left[\tilde{v}_{a}^{+}(S)-\tilde{v}_{a}^{+}(S \backslash\{i\})\right] \quad \\
& i=1,2, \cdots n
\end{aligned}
$$

Where $|S|$ refers to the number of elements in the set, $\psi_{i}\left(\widetilde{v}_{\alpha^{-}}\right)$and $\psi_{i}\left(\widetilde{v}_{a^{+}}\right)$are the left and right endpoints of the interval fuzzy Shapley values of each partner corresponding to different significance levels $\alpha$.

When the actual total risk loss reduction value is $\widetilde{v}(S)^{*}$, the corresponding $\alpha^{*}$ can be calculated according to the properties of the symmetrical triangular membership function. According to formulas (2) and (3), the interval fuzzy Shapley value $\left[\psi_{i}\left(\widetilde{v}_{\alpha^{-}}\right), \psi_{i}\left(\widetilde{v}_{\alpha^{+}}\right)\right]$of each partner can be written corresponding to $\alpha^{*}$. If $\psi_{i}\left(\widetilde{v}_{\alpha} \alpha^{-}\right) \leq \psi_{i}\left(\widetilde{v}_{\alpha^{+}}\right)$, the number on the same side of the interval can be selected as $\psi_{i}\left(\widetilde{v}_{\alpha^{*}}\right)^{*}$; on the contrary, if $\psi_{i}\left(\widetilde{v}_{\alpha}{ }^{-}\right) \geq \psi_{i}\left(\widetilde{v}_{a^{+}}\right)$, the corresponding shared value interval $\left[\psi_{i}\left(\widetilde{v}_{a^{+}}\right), \psi_{i}\left(\widetilde{v}_{\alpha}{ }^{-}\right)\right]$can be written based on formulas (2) and (3). The number of different sides of the interval can be selected as $\psi_{i}\left(\widetilde{v}_{a^{*}}\right)^{*}$, where $\psi_{i}\left(\widetilde{v}_{\alpha^{*}}\right)^{*}$ is the shared value of each partner corresponding to the total risk loss reduction value $\widetilde{v}(S)^{*}$, which can be used to share the total risk loss reduction value $\widetilde{v}(S)^{*}$.

\section{Case analysis}

Taking a rural domestic sewage treatment project as an example, if the change of market demand ensues risks and the government department manages the risks independently, the loss value of the project can be reduced by 0.8 million. If the enterprise manages the risk independently, the loss value of the project can be reduced by 0.21 million. If the government and the enterprise cooperate to jointly manage the risk, the loss value of the project can be reduced by 1.07 million yuan.

According to formula (1), the risk loss fuzzy function of government 1 , social capital 2, and their cooperation are as follows:

$$
\mu_{1}(\tilde{v})=\left\{\begin{array}{cl}
(\tilde{v}-80) / 3 & \tilde{v} \in[80,83] \\
(86-\tilde{v}) / 3 & \tilde{v} \in[83,86] \\
0 & \text { others }
\end{array} \quad \mu_{2}(\tilde{v})=\left\{\begin{array}{cl}
(\tilde{v}-21) / 3 & \tilde{v} \in[21,24] \\
(27-\tilde{v}) / 3 & \tilde{v} \in[24,27] \\
0 & \text { others }
\end{array}\right.\right.
$$




$$
\mu_{12}(\tilde{v})=\left\{\begin{array}{cl}
(\tilde{v}-101) / 3 & \tilde{v} \in[101,104] \\
(107-\tilde{v}) / 3 & \tilde{v} \in[104,107] \\
0 & \text { others }
\end{array}\right.
$$

The $\alpha$ cut set of the triangular fuzzy payment function can be obtained by changing the confidence $\alpha$ in interval $[0,1]$ with step size of 0.1 , as shown in Table 1. The value interval of Shapley value at different confidence levels $\alpha$ is calculated from equations (2) and (3), as shown in Table 2.

Table 1. The $\alpha$ cut set of the triangular fuzzy number

\begin{tabular}{|c|c|c|c|c|c|c|c|c|c|}
\hline \multirow{2}{*}{$\tilde{v}(s)$} & \multicolumn{9}{|c|}{$\alpha$} \\
\hline & 0.1 & 0.2 & 0.3 & 0.4 & 0.5 & 0.6 & 0.7 & 0.8 & 0.9 \\
\hline$\tilde{v}(1)$ & $\begin{array}{l}{[80.3,} \\
85.7]\end{array}$ & $\begin{array}{l}80.6, \\
85.4]\end{array}$ & $\begin{array}{l}80.9 \\
85.1]\end{array}$ & $\begin{array}{l}81.2, \\
84.8]\end{array}$ & $\begin{array}{l}81.5, \\
84.5]\end{array}$ & $\begin{array}{l}81.8, \\
84.2]\end{array}$ & $\begin{array}{l}82.1, \\
83.9]\end{array}$ & $\begin{array}{l}82.4, \\
83.6]\end{array}$ & $\begin{array}{l}{[82.7,} \\
83.3]\end{array}$ \\
\hline$\tilde{v}(2)$ & $\begin{array}{l}{[21.3,} \\
26.7]\end{array}$ & $\begin{array}{l}{[21.6,} \\
26.4]\end{array}$ & $\begin{array}{l}{[21.9} \\
26.1]\end{array}$ & $\begin{array}{l}{[22.2,} \\
25.8]\end{array}$ & $\begin{array}{l}{[22.5,} \\
25.5]\end{array}$ & $\begin{array}{l}{[22.8} \\
25.2]\end{array}$ & $\begin{array}{l}{[23.1,} \\
24.9]\end{array}$ & $\begin{array}{l}{[23.4,} \\
24.6]\end{array}$ & $\begin{array}{l}{[23.7,} \\
24.3]\end{array}$ \\
\hline$\tilde{v}(12)$ & $\begin{array}{c}{[101.3,} \\
106.7]\end{array}$ & $\begin{array}{l}{[101.6} \\
106.4]\end{array}$ & $\begin{array}{c}{[101.9,} \\
106.1]\end{array}$ & $\begin{array}{c}{[102.2,} \\
105.8]\end{array}$ & $\begin{array}{c}{[102.5} \\
105.5]\end{array}$ & $\begin{array}{c}{[102.8,} \\
105.2]\end{array}$ & $\begin{array}{c}{[103.1,} \\
104.9]\end{array}$ & $\begin{array}{c}{[103.4} \\
104.6]\end{array}$ & $\begin{array}{c}{[103.7,} \\
104.3]\end{array}$ \\
\hline
\end{tabular}

Table 2. The value interval of Shapley value at confidence levels $\alpha$

\begin{tabular}{cccccccccc}
\hline \multirow{2}{*}{$\begin{array}{c}\text { Shapley } \\
\text { value }\end{array}$} & 0.1 & 0.2 & 0.3 & 0.4 & 0.5 & 0.6 & 0.7 & 0.8 & 0.9 \\
\cline { 2 - 9 } & {$[80.15$,} & {$[80.3$,} & {$[80.45$,} & {$[80.6$,} & {$[80.75$,} & {$[80.9$,} & {$[81.05$,} & {$[81.2$,} & {$[81.35$,} \\
& $82.85]$ & $82.7]$ & $82.55]$ & $82.4]$ & $82.25]$ & $82.1]$ & $81.95]$ & $81.8]$ & $81.65]$ \\
$\psi_{1}(v)$ & {$[21.15$,} & {$[21.3$,} & {$[21.45$,} & {$[21.6$,} & {$[21.75$,} & {$[21.9$,} & {$[22.05$,} & {$[22.2$,} & {$[22.35$,} \\
& $23.85]$ & $23.7]$ & $23.55]$ & $23.4]$ & $23.25]$ & $23.1]$ & $22.95]$ & $22.8]$ & $22.65]$ \\
\hline
\end{tabular}

Ten thousand yuan

If the actual reduced risk loss value of the PPP project is 1.05 million yuan, it can be seen from Table 1 that the risk loss value of 1.05 million is between 1.049 and 1.052 million, so the significance level $\alpha^{*}$ is between 0.6 and 0.7 , and it is located on the right side of the $\alpha$ interception center. Finding the corresponding $\alpha^{*}=0.67$. Finding the cut sets of $\widetilde{v}(1), \widetilde{v}(2)$, and $\widetilde{v}(12)$. Then, the value range of the interval fuzzy Shapley value of government 1 is calculated as $[81.005,81.995]$ corresponding to $\alpha^{*}=0.67$. Similarly, the value range of interval fuzzy Shapley value corresponding to enterprise 2 is [22.01, 22.995]. Taking the right end point of the interval fuzzy Shapley value as the risk sharing value of government 1 and enterprise 2, it is 81995 and 22995 yuan, respectively.

\section{Disclosure statement}

The author declares that there is no conflict of interest.

\section{References}

[1] Jin XH, 2010, Neurofuzzy Decision Support System for Efficient Risk Allocation in Public-Private Partnership Infrastructure Projects. Journal of Computing in Civil Engineering, 24(6): 525-538.

[2] He T, Zhao G, 2011, Risk Sharing of PPP Projects Based on Stochastic Cooperative Game Model. Systems Engineering, (4): 88-92. 
[3] Wang L, Zhao M, Peng R, 2017, Research on Risk Sharing Strategy of PPP Model Based on ANP Shapley Value. Financial Research, (6): 40-50.

[4] Liu C, Song L, Meng J, 2018, Interval Fuzzy Shapley Value Method for Risk Sharing of Water Diversion PPP Project. Hydropower and Energy Science, (6): 162-166. 